\title{
The Use Of "Minato" As A Character Learning Self-Study Application And Its Effects: An Introduction To Beginner Japanese Language Learners At Indonesian Higher Education Institution
}

\author{
Taku Okamoto, Maharani Patria Ratna, Sriwahyu Istana Trahutami \\ Japan Foundation \\ Diponegoro University \\ E-Mail: sriwahyuistanatrahut@lecturer.undip.ac.id
}

\begin{abstract}
Self-learning is a learning method that answers the challenges of learning in the distance learning era that the government has set due to the Covid-19 pandemic. This study describes the effectiveness of using Minato as a selflearning medium for beginner Japanese learners at the Vocational School, Diponegoro University. As a learning medium, Minato has several classes that can be taken for learning basic Japanese independently, including self-learning hiragana and katakana, dialects, and kanji. The method used in this research is a survey method used as a medium to determine the effectiveness of using Minato. Before carrying out self-learning learning, students were asked to fill out a survey and pretest. After learning with Minato, learners returned to fill out surveys and posttests. Survey and test results will be used to determine the effectiveness of using Minato. The result of this research is that Minato is very effective for independent learning. This is concluded based on a questionnaire distributed to students, student electronic certificates, and teacher opinions.
\end{abstract}

Kata kunci: Minato; self-learning; hiragana; katakana, online

\section{Introduction}

Based on the 2018 Japanese Language Education Institute (Japan Foundation) Survey results, the number of Japanese language learners in Indonesia decreased slightly compared to the 2015 survey but was still above 700,000, the second-highest after China. In Southeast Asia, Indonesia accounts for about $60 \%$ of all Japanese learners in the area. Starting in 2017, Vocational School was established at Diponegoro University, a national university in Central Java, Indonesia. At the Vocational School, students take vocational education for three years (Diploma 3 / D3). It is different from undergraduate students (Strata 1 / S1), who take four years of academic education. After graduating, vocational school students get a Diploma (Associate Expert / A.Md) with applied knowledge and skills applicable in the job market.

In 2019, vocational schools began to offer Diploma 4 (D4) programs equivalent to a bachelor's degree. In the D4 program, students will receive four years of vocational education. D4 students will have an applied bachelor's degree (S.Tr). At the same time, a new curriculum should be compiled to support the learning of D4 students. One of them is a course called "Hiragana and Katakana."

Reflecting on hiragana and katakana teaching at D3, students tend to be passive in class, and 
class activities tend to be monotonous. Therefore, as the course rearranges, we will be experimenting with new teaching styles by adding elements that promote self-learning. In recent years, Indonesia has been actively developing Information and Communication Technology (ICT). In particular, electronic learning (e-learning) in education is one of the focuses of ICT development. The aim is to improve the overall quality of education in the country. The research objective is to design and implement courses that utilize ICT in Japanese beginner-level Japanese learning offered by Indonesian higher education institutions and provide independent "higher education" learning opportunities. An example of using Japan Foundation Courses (JF courses) is at the Japan Foundation Manila, Philippines (JFM) (Waguri et al., 2019). At JFM, teachers have included lessons "Hiragana Course" and "Katakana Course" since 2017. This paid course is held for approximately one month in three face-to-face sessions every Saturday by providing learning to read and write letters online. In Indonesia, research was done by Tasia [Tasia, 2015] mentioned that in a state high school in Semarang, students find it challenging to differentiate hiragana and katakana with similar shapes, long vowels, and diphthong.

\section{Methods}

This research is a descriptive study with a survey method. The data was collected through a questionnaire as a data collection medium. In the initial survey, researchers asked eight questions about Japanese learning experiences and e-learning learning experiences. The surveyed subject is one of the Applied Foreign Language study program courses at the Vocational School of Diponegoro University, a national university in Central Java, Indonesia. The course is called "Hiragana Katakana" which is offered every even semester.

The number of students enrolled was 108 people, who were randomly divided into three classes. Lectures are held for 16 weeks from 19 February to 11 June 2020, with a duration of 100 minutes per face-to-face. The real face-to-face is 14 times, excluding midterm and final semester exams. All students who take this course have learned to use "Introduction to Marugoto <Katsudo> A1" produced by JF. The results of a questionnaire of 108 Vocational School students who were beginner Japanese learners showed that 34 students $(31.5 \%)$ had previous experience of learning Japanese, while 74 students $(68.5 \%)$ did not. It means that nearly $70 \%$ of students have never studied Japanese before entering university.

Thirty-four students who answered "yes" to questions regarding previous Japanese learning experiences were further asked, "where did you study Japanese (multiple answers allowed)?", Obtained 40 answers. Most of them had a learning experience in "high school" (21 students, 52.2\%), followed by "self-study" (13 students, 32.5\%). Also, $15 \%$ answered that they had studied Japanese during elementary or junior high school. In addition to the questions above, the researcher also asked all respondents about their learning experience through e-learning. The result was that 38 students $(35.2 \%)$ had learning experiences through e-learning, while 55 students $(50.9 \%)$ did not. On the other hand, 15 students (13.9\%) said they "don't know." 


\section{Result and Discussion}

\subsection{Introduction to the self-study course "Minato"}

In this study, researchers used hybrid learning, which combines independent learning through online learning and face-toface learning in class. Hybrid learning is a mixed learning method, between face-to-face learning and online learning [Culture, 2021]. As mentioned above, the researchers introduced the "Hiragana A1 Self-Study Course" and the "A1 Katakana Self-Study Course," which are open to the public on the "Minato" platform developed by the Japan Foundation Japanese-Language Institute. "Hiragana A1 self-study course" and "Katakana A1 self-study course" are courses where learners can learn how to read and write hiragana or katakana. This course is designed to interactively learn pronunciation, practice vocabulary, and type letters (Ishii et al., 2017). Handwritten teaching materials are also provided.

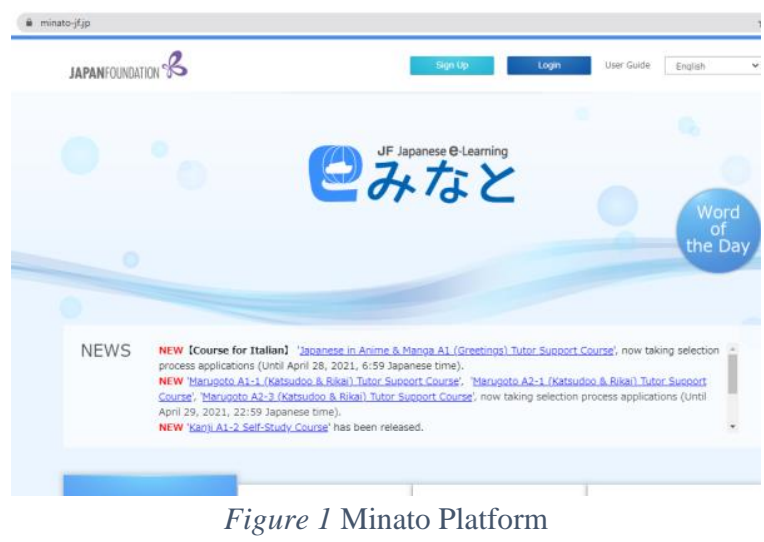

This course also combines many elements of e-learning materials developed by JFKC, namely "Marugoto + (plus)" and associative illustration materials for the "HIRAGANA Memory Hint" and "KATAKANA Memory Hint" applications.
As a series of lessons learned in the Marugoto textbook, researchers feel the need to add Minato as an independent learning medium. By introducing Minato to Japanese learners, learners will get a new atmosphere in Japanese language learning that does not dwell on textbooks alone (the conventional way). Minato's various features provide space for Japanese learners to learn Japanese in a new way by taking advantage of advances in ICT. It is the main background for Minato's selection in the application of independent learning in the Hiragana Katakana course.

Minato is a medium for learning Japanese letters and as a medium for learning Japanese as a whole. It can be seen in the 67 types of courses offered by Minato, including courses based on various foreign languages in the world for learning Japanese. Apart from hiragana and katakana, Minato offers self-learning of basic kanji, reading, dialects, Etc. Thus, Minato can be used for early Japanese learners with various language skills. Also, Minato is presented for free by The Japan Foundation.

\subsection{Self-Learning Process}

The course "Hiragana and Katakana" is held for 16 weeks, divided into the first half and the second half. The orientation and learning activities are carried out in the same order in the first half and the second half. However, in this article, we will focus on describing hiragana learning in the first half. In the first week of class, the teacher provides orientation and explains the course syllabus, then explains a survey held in the middle of learning to ask for cooperation from students. After that, the researcher introduced "Minato" in detail and explained how to use it. 
After the explanation is complete, students are asked to register an account at Minato immediately. Then, students are given a pre-questionnaire and a pre-test. Meetings in weeks 2 and 3 are a period of self-study. Students are given the task to learn hiragana using the self-study course "Minato." The standard study time to completion specified in the self-study course is 14 hours. Students can continue studying at their favorite place during the self-study period, such as home, or come to class during Hiragana Katakana course hours, or continue their independent learning.

Students are asked to submit a screenshot taken of the "status," which can be seen on the learning progress screen in the "Minato" system in the second week to ensure learning progress during the self-study period. At the end of the self-study period in week 3 , the "electronic certificate" and "learning notes" that can be downloaded on the Minato platform must be submitted in PDF form to the teacher. At the time of certificate collection, 107 out of 108 students sent their certificates according to the deadline (One person who exceeds the deadline for health reasons, the certificate is collected following). Based on this, it can be understood that most students show responsibility for carrying out tasks by the instructions that have been set. To determine the effect of learning after using Minato, researchers compared the students' pre-test and post-test scores.

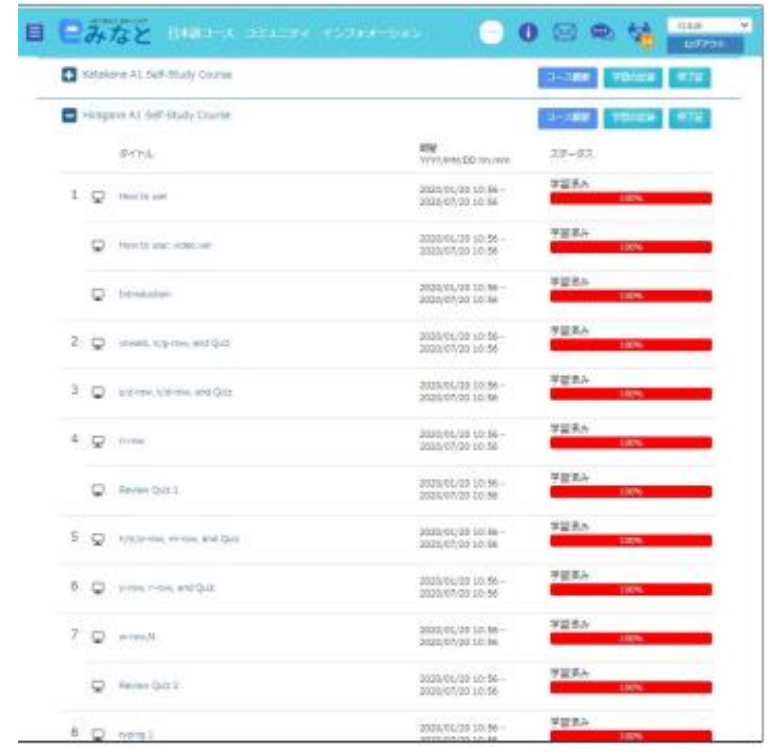

Figure 2 Screen Shot of Progress

\subsection{Effectivity of Minato}

After using Minato, based on surveys, post-tests, certificates, and student learning notes, it can be understood that Minato is beneficial as a medium for independent learning. Students' success in taking hiragana and katakana courses provided by Minato has similar effectiveness to conventional learning that was carried out before the application of the self-learning method. The effectiveness of Minato is increasing due to the Covid-19 pandemic, which causes learning at universities in Indonesia to be carried out through distance learning / online learning. With the pandemic, students must prioritize independent learning carried out in their respective homes. Minato is a medium that is very helpful for students and teachers in bridging the delivery of material.

Through Minato, students can do independent learning interactively. Also, Minato packs how the understanding of hiragana katakana is conveyed, so it is easy to remember. Also, the conventional learning process that generally occurs by listening to 
lectures from teachers has decreased dramatically. Students get new experiences by learning independently with discovery learning. Students become independent learning experiences with the teacher as facilitator.

The teachers also felt the effectiveness of Minato. Teachers of hiragana and katakana courses feel that the self-learning method is a contemporary method expected to be applied to various subjects. Self-learning focuses on studying students to conduct brainstorming so that students' critical thinking skills are increase. So, it does not rely on one-way lectures like conventional learning models. The learner as a bridge will provide directions, answer student questions and provide affirmations in essential conclusions to the learner. However, of course, the learning process is not centered on the teacher but the students.

\section{Conclusions}

This article discusses the effects and advantages of introducing the self-study course "Minato" in the Japanese writing course offered at the D4 / applied bachelor level Applied Foreign Language Study Program, Diponegoro University Vocational School. This study's results were to learn Japanese letters (hiragana and katakana), students could gain understanding using an independent learning platform. This is reinforced by the hiragana katakana course teacher's opinion, who states that students successfully acquire the same skill level as conventional teaching style teaching. Furthermore, it can be said that the introduction of independent learning can increase student independence. Through this research, the researcher believes that the opportunity to realize "student style" education can be done by providing the right media through ICT. This is proven through this research. Independent learning is not only beneficial for students but also beneficial for teachers.

This article was presented at the 3rd Annual Conference on Japanese Language Education in South Asia (JLESA'20-21).

\section{References}

Gunji, Takuya. (2012). A Study of Hiragana and Katakana Pedagogy for Cantonese Speakers - Using the origin of Hiragana and Katakana. Nihon Gakkan. 15. 38-47. 10.32319/Gakkan/2012/vol15/GUNJ I.

Japan Foundation Kansai International Center (2019) "Classes using the" Hiragana A1 Self-study Course "class at KC" KC clip <https://kansai.jpf.go.jp/clip/minato/l esson.html> (August 23, 2020)

Kentaro Higashi (2019) "Using Online Teaching Materials for Japanese Language Education" (Lecture Material at the 24th Mexican Japanese Language Education Symposium) <https://kansai.jpf.go.jp/clip/minato/ minato_2018d.pdf> (2020 August 23, 2014)

Kentaro Higashi (2019) "Under development!" JF Nihongo eLearning Minato "" "Japanese Language Education Correspondence Japanese Language Education News" <https://www.jpf.go.jp/j/project/japa nese/teach/ tsushin / news / 201902.html> (August 23, 2020)

Kentaro Higashi, Naoko Miyake, Wei, Nobuyuki Kitaguchi, Satoshi Miyajima (2020) "Operation status and results of the" JF Japanese eLearning Minato "self-study course- 
focusing on the number of students, completion rate, and satisfaction-" "International exchange Bulletin of Japanese Language Education, Japan Foundation, 16, 123-135

Mari Nobuoka, Natsumi Waguri, Hideaki Ito, Yukino Yamashita, Keiko Kawashima, Takashi Miura (2017) "Composition and Future Prospects of" JF Nihongo e-Learning Minato "" "Bulletin of the Japan Foundation Japanese Language Education" 13, $125-132$

Ministry of Internal Affairs and Communications (2019) "Republic of Indonesia" "World Information and Communication Situation" $<$ https://www.soumu.go.jp/gict/country/indonesia/index.html > (August 23, 2020)

Ministry of Education and Culture (2021) " Even Semester Learning Will Use the "Hybrid 'Method" <

https://itjen.kemdikbud.go.id/public/ post/detail/pembelajaran-semestergenap-akan-menggunakan-metodehybrid\#: :text=ITJEN\%20KEMEN DIKBUD,-\%22Mencerdaskan\%20K ehidupan\%20Bangsa\&text $=$ Hybrid $\%$ 20learning\%20adalah $\% 20$ metode $\% 2$ Opembelajaran,muka\%20dengan $\% 20$ pembelajaran $\% 20$ dalam $\% 20$ jaringan .> (April 26, 2021)

Nanae Kumano, Hideaki Ito, Yuto

Kitamura, Tomohisa Yamada (2019)

"What is needed to utilize e-learning materials from public institutions (JF, universities, Agency for Cultural Affairs) in Japanese language education?" "CASTEL / J (Japanese Language Education Support System
Study Group) 8th International

Convention Proceedings", 20-27

Natsumi Waguri, Carmen Theta Keorani

Biscara, Takashi Miura, Junji

Katagiri (2019) "Practice of Japanese

Online Course Operation What We

Have Seen from the Practices of the

Philippines, Malaysia, and

Indonesia") 8th International

Convention Proceedings", 12-19

Tasia, Anindya (2015) "Analysis of Students

Errors in Writing Hiragana and

Katakana at SMAN15 Semarang"

Semarang State University

The Japan Foundation (2020) "Current

Situation of Japanese Language

Education Overseas From the 2018

Survey of Japanese Language

Education Institutions"

Tomomi Chiba and Nanae Kumano (2017)

"Development and operation of

Japanese language online course in"

JF Nihongo e-Learning Minato "-To

continue self-study in e-learning"

"21st European Japanese Language

Education Symposium Report

Proceedings of presentations, 372-

377

Universitas Diponegoro (2018) Sekolah

Vokasi

<https://um.undip.ac.id/fakultas/detai

$1 / 13$

$>$ (August 23, 2020)

Yoko Ishii, Yosuke Kasai, Tomomi Chiba

(2017) "Development of an online course for learning interactively"

(Proceedings of the 2017 Spring

Meeting of the Japanese Language

Education Society)

<http://www.nkg.or.jp/pdf/yokou-

17backnumber28381.pdf $>$ 